\title{
Health Sector Reform Agenda in an Insecure Nigerian State: Issues, Problems and Prospects
}

\author{
Ignatius Uche Nwankwo \\ Nneka Ihuoma Okofor \& \\ Adaeze Olisa \\ Department of Sociology/Anthropology \\ Nnamdi Azikiwe University, Awka \\ Anambra State, Nigeria
}

DOI: 10.36108/NJSA/3102/11(0150)

\begin{abstract}
The Nigerian state is confronted with several health challenges such as high morbidity rate arising from prevalence of communicable diseases, improper disposal of solid wastes and other forms of environmental pollution, inadequately distributed and poorly equipped health institutions among others. In response to these challenges, government has instituted health sector reform as a key strategy to ameliorate the problems. In view of the worrisome security challenges that the country presently faces such as the Boko Haram insurgence, kidnapping, politically and economically motivated assassinations among others there are apprehensions on whether health reforms will ever succeed. This paper examines the link between health and insecurity with reference to how Nigeria's pursuit of health reform agenda is affected by rising state of insecurity of lives and properties in the country. It was strongly emphasized that economic empowerment through employment and microfinance initiatives, as well as aggressive public enlightenment will reduce tendencies towards insecurity.
\end{abstract}

Keywords: health, insecurity, health reform, health security, national health insurance scheme

\section{Introduction}

Nigeria's Federal Ministry of Health has consistently stated her commitment to reducing morbidity and mortality rates arising from communicable diseases to the barest minimum; and to reverse the increasing prevalence of non communicable diseases, meet global targets on the elimination and eradication of diseases, and to significantly increase life expectancy and quality of life of Nigerians. That way, effective, quality and affordable health services would be delivered to the citizenry (Federal Ministry of Health, FMOH, 2001; 2004).

Unfortunately despite Nigeria's well articulated vision and mission statements, World Health Organization (2000) ranked Nigeria a dismal 187th position among 191 United Nation member states. Health indicators for Nigeria showcase a country with myriad of health problems, with maternal mortality ratio ranging from 704 (FOS/UNICEF, 2000) to 1500 (UNFPA, 2002) per 100000 live births; and infant mortality rate of 115 per 1000 live births (the global average is 60) and under-5 mortality rate of 205 per 1000 (FMOH,2007). Furthermore, more than 1 million children die each year from preventable diseases. Nigeria is also the only country in Africa not to have 
eradicated poliomyelitis. The vaccination programme in the country only covers about $70 \%$ of those it is intended for $(\mathrm{FMOH}, 2004$; Chukwunwike, 2005).

Nigeria has one of the lowest national health budgets in Africa. Not only is the proportion of the Gross Domestic Product (GDP) spent on health very low, but there is also enormous inequity in the amount spent on health services among different parts of the country. Above all, there are also differences in the capacity of Nigeria's 774 local governments to provide primary health care which ought to be the cornerstone of the healthcare delivery system. Thus under-funding of the health sector contributes to low quality of health services in the country (Nwokeoma, 2009; Asuzu, 2002).

Many health facilities at primary, secondary and tertiary levels are dilapidated, totally dysfunctional or operating below average capacity. The health referral system, to say the least, is not operational, a situation compounded by poor remuneration and low motivation of health personnel. All these translate to inefficient and ineffective health care delivery (Chukwunwike, 2005). The obvious victims of this state of affairs are healthcare seekers most of whom have become disillusioned and dissatisfied with low quality of health care. Such consumers also have to contend with the problem of fake, sub-standard, adulterated and unregistered drugs (NAFDAC, 2003). Supplies of safe and affordable drugs and consumables are irregular (Ebigwei, 2005).

Only about a quarter of health spending in Nigeria is through the public sector - so it is not surprising that the poor suffer the most from lack of access to health services. They cannot afford the costs of direct payments - not only must people pay for health services in the private sector, but many public health services charge a fee as well. A high proportion of the total spending on health is done by households. Between 1998 and 2002, an average of $64.5 \%$ of the total health expenditure on health came from households. This is a very high (Ogunbekun, 2004).

Nigeria's development efforts have over the years been characterized by lack of continuity, consistency and commitment (3Cs) to agreed policies, programmes and projects. There is also an absence of a long-term perspective. The cumulative effect has been growth and development of the Nigerian economy without a concomitant improvement in the overall welfare of the citizens. Disregard for the $3 \mathrm{Cs}$ has resulted in rising unemployment, unequal access to health services and rising levels of poverty. It is against this backdrop that the need to reform the health service delivery system for enhanced performance was embarked upon (Odutola, 2004; Asuzu, 2002). It was envisaged that health reforms will reposition the Nigerian public health sector to be responsive to the health needs of Nigerians and to ensure healthier, longer and more productive lives (Odutola, 2004; Asuzu, 2002; Berman, 1995). 


\section{Conceptual Relevance of the Health Reform and Insecurity Discourse} Health System is an organizational framework for the distribution of health care needs of a given community. It is a fairly complex system of inter-related elements that contribute to the health of people - in their homes, educational institutions, in work places, the public (social or recreational) and the psychological environments as well as in health and health-related institutions (Asuzu, 2002). Health Sector Reform refers to a sustained process of fundamental change in policy, regulation, financing, provision of health services, re-organization, management and institutional arrangements which is led by government, and designed to improve the performance of the health system for better health status of the population (Federal Ministry of Health, 2004). It has also been defined as sustainable, purposeful change aimed at improving the health sector (Berman, 1995).

Health Sector Reform Programme (HSRP) is a document that establishes the framework, including goals, targets and priorities that should guide the action and work of the Federal Ministry of Health and, to some extent, State Ministries of Health and Development Partners in respect of health reforms (World Bank, 2000). The document sets the tempo and direction for strategic reforms and investment in key areas of the national health system, within the context of the overall government macroeconomic framework. The current health sector reform programme in Nigeria sets 2015 as a target date for realization of most of its goals. Health security involves safety against pandemics, diseases and other threats to health. It is usually attained through human security approach where people participate deliberate and take informed decisions related to optimum protection of their health in support of national development drives.

There is no consistently applied, universal package of measures that constitutes health sector policy reform. Rather, the precise agenda for reform will be defined by reviewing how well existing policies, institutions, structures, and systems deal with issues of efficiency, access, cost containment, and responsiveness to popular demand (Federal Ministry of Health, 2007). The relative importance of these issues will vary between less developed countries, industrialized countries, and countries in transition from a communal economy. This underscores the socio-cultural context of health reforms. In less developed countries, reform strategies need to address the issues of extending the coverage of basic services to under-served populations, improving poor service quality, and addressing the inequitable distribution of resources, in the context of very limited institutional capacity. In many of the world's richer countries, cost containment has been the driving force behind reform. However, the need for systems to ration health care provision in line with national policy objectives is common to all countries. Each country has its own agenda for health sector development. This is because of differences in values, goals and priorities. 


\section{Broadened View of Security and Insecurity in the Context of Health Discourse}

The concept of security has for too long been interpreted narrowly: as security of territory from external aggression, or as protection of national interests in foreign policy or as global security from the threat of a nuclear holocaust. It has also been related more to the nation-state than to people. Often forgotten is the fact that security is a major legitimate concern of ordinary people. This paper views security beyond a mere military and police problem. It is conceived broadly as the protection from the threat of disease, hunger, unemployment, crime, social conflict, violence, political repression, and environmental hazards (UNDP Human Development Report, 1994).

Security is thus an all-encompassing condition in which individual citizens live in freedom, peace, and safety; to participate fully in the process of governance; enjoy the protection of fundamental rights; have access to resources and the basic necessities of life; and inhabit an environment which is not detrimental to their health and well-being. Security has broadened to incorporate political, economic, social, and environmental matters (Elbe, 2005; 2006). At the heart of this new approach is a paramount concern with the security of people (South African Department of Defense, 1996).

The issues of hunger, poverty, proliferation of weapons, landmines, authoritarianism, environmental pollution and degradation, social injustice, political exclusion, crime, human rights abuse, illiteracy, economic deprivation, corruption, and maladministration, which human security seeks to solve, must be critically addressed in making security decisions. Many nation states are now having human security as the foundation and new thrust of their security agenda and deemphasizing coercion and deterrence approach, which is state-centric. When the desired protection of people in conflict, political, economic, social, and environmental matters is deficient, insecurity will prevail. The insecurity situation in Nigeria has worsened over the years particularly as the Boko Haram insurgence compounded her deplorable credentials in the areas of widespread poverty and hunger, illiteracy, and generally poor level of health and other social services

\section{Security and Health Interface: A Reality of Contemporary Globalised World}

A recent development in global health discourse has been the way in which health issues are linked to security situations. To fully understand the relationship between security and health, this paper would briefly describe the origins of this development. One of the drivers for this development is the awareness of the potential for fast-moving epidemics to deliver shocks to the global economy. In 2007 the WHO devoted its annual World Health Report to 'Global Public Health Security in the $21^{\text {st }}$ Century.'

Since the Cold War, and especially after the 9/11 terrorist attacks on the United States, issues such as poverty, climate change and HIV/AIDS have also become framed as security threats (NIC, 2002; Elbe, $2005 \& 2006$ ). This is by 
virtue of their negative impact on economic and political stability, both within countries and across borders. Against the above background, a US Strategy on HIV/AIDS argued that the pandemic needed to be seen not only in terms of threat to human health or national development, but also as a threat to 'international security' impacting on affected countries and beyond (NIC, 2002). The strategy noted that 'as the HIV/AIDS pandemic erodes economic and security bases of affected countries, it may be a 'war-starter' or 'waroutcome determinant'. It also described how 'HIV directly impacts on military readiness and manpower, causing loss of trained soldiers and military leaders', and how 'worldwide peacekeeping operations will become increasingly controversial as militaries with high infection rates find it difficult to supply healthy contingents.'

The National Intelligence Council returned to the subject in 2002, issuing a report on five countries (Nigeria, Ethiopia, Russia, China and India) which were considered strategically important to the United States. The Report identified links between disease, political instability, threats to socioeconomic development and military effectiveness (NIC, 2002). By 2005, the Global Business Coalition on HIV/AIDS was making links between AIDS, economic decline and potential terrorist threats, including speculations on how a steady stream of orphans might be exploited and used for terrorist activities (Neilson, 2005).

At one level, the linkage of 'health' to 'security' can be viewed positively in the sense that it highlights the concept of human security, which shifts the focus of security discourse away from mere state security and more towards people and their basic rights and needs. At another level, there are risks associated with extending the scope of security into the health and development spheres. Importantly, framing health in terms of security has emerged and gained tremendous support from global power centres. Accordingly, foreign policy and intelligence agencies of the most powerful states are drawn into the domain of health within low- and middle-income countries (Lee and Mclanes, 2004). Consequently, health policies and programmes may be co-opted into serving economic and political projects, especially in the post 9/11 landscape in which counterterrorism has emerged as an overriding policy priority, and which has made concern for health and human rights a focal issue.

It is however noteworthy that by focusing and criticizing the destabilizing effects of HIV/AIDS and poverty, civil society groups helps to generate muchneeded attention and resources for the long neglected health concerns of poorer countries. Nonetheless, the linking of 'health' with 'security' is not necessarily a win-win situation. Crucially, those who use security arguments to boost health in the political agenda often fail to control where the logic of security takes them. While the linking of health and security generates more attention and resources for health, an overdose of such attention towards protection of health of military personnel or their families and relatives could be counterproductive. Furthermore, the use of health as an instrument of foreign policy, 
or as a bridge to secure better control over strategic resources in other countries, is also evident. For example, the 2002 NIC report on HIV/AIDS stated in relation to Nigeria that HIV/AIDS could contribute to deterioration of state capacity in a country that is very important to United States energy, security and counterterrorism strategies (CSIS, 2005). This formed part of the context for massive increases in US aid for Nigeria in recent years. Indeed, through 2007 PEPFAR, the USA allocated US\$578 million to Nigeria, far outstripping other donors (CSIS, 2005). As part of this, PEPFAR is creating a total HIV surveillance system for the Nigerian military; conducting prevention initiatives; creating more reliable supply chains; and organizing treatment for military personnel and dependants who are living with HIV. Again, to an extent this might be welcomed. However, HIV/AIDS is a multidimensional problem affecting all sectors of society, including the military.

The HIV/AIDS-security link has also drawn attention to the spread of HIV via military and security forces in conflict or peacekeeping situations. But questions are now asked as to whether targeting the military sector and privileging certain parts of society because of their relevance to US strategic goals and excluding others is not problematic on the long run (Elbe, 2005). While saving lives in the short term too much emphasis on HIV/AIDS relief to the military could perpetuate a closed political loop that is detrimental to wider human security. It also fails to address deeper-rooted social determinants of health.

The trade-offs associated with linking security to health is illustrated also with the prevention and control of disease outbreaks. Whilst protecting the health security of populations is a good strategy, it is important also to ask who is being secured, from what, how, and at whose cost? The surveillance of public health threats requires upgrading of data capture and information systems. This is because the focus on cross-border infectious disease control may mask structural problems in global public health, leading to solutions which benefit the rich more than the poor.

Lee and Mclnnes (2004) observe that linking health to security creates a complex political space that requires discussion and research, particularly in relation to three issues:

- The issue of determining what is and is not a security problem. This is very important because same 'powerful actors' who determine what constitutes security issue are also responsible for shaping international responses to those threats.

- The issue of efforts to address health problems deemed important through a security lens, rather than more objective measures of need is another danger. This approach may likely distort health priorities. For instance, how could the conceptualization of health as poverty, justice or human rights issue be reconciled, for example, with strategic objectives linked to 'fragile states', 'failed states' or 'rogue states'? What are the consequences of health being used as an instrument of foreign policy? 
- The issue of undue concern with security within the health sector which often runs counter to the principles of decentralization and community empowerment. Negation of these principles may reinforce problematic aspects of health policy which may lead to certain communities being demonized as 'security threats' (Elbe, 2006). For instance, the desire to enhance security may lead donors to prioritize bilateral funding mechanisms at the expense of multilateral channels.

\section{Theoretical Perspective}

This paper is anchored on two related theoretical - Strain and Rational Choice theories. With regard to strain theory, Merton argued that deviance resulted from the culture and structure of society itself (Haralambos and Holborn, 2004). According to him, in a smoothly functioning society, deviance will be limited because most people share common cultural goals and agree upon the appropriate means for reaching them. However, societies that do not provide sufficient avenues to reach these goals may lack agreement about the appropriate means by which people may achieve their aspirations. Deviance may be common in such societies because people may be willing to use whatever means they can to achieve their goals.

The implementation of health reform agenda in Nigeria is usually characterized by bottlenecks because many people (including health workers and administrators) feel strain due to exposure to cultural goals they are unable to obtain because they do not have access to culturally approved means of achieving them. In this instance, the goals may be material possessions and money; the approved means include commensurate salary, allowances and incentives which are usually inadequate, hence some health administrators and professionals may be tempted to adopt corrupt means which could derail progress towards reform.

On the other hand, the Rational Choice Theory, first propounded by James Coleman (1926-1995) argued that patterns of behavior in societies reflect the choices made by individuals as they try to maximize their benefits and minimize their costs. In other words, people make decisions about how they should act by comparing the costs and benefits of different courses of action. In the light of this theory, challenges to health reform in Nigeria could be explained as aftermath of rational choices made by Nigerians, particularly those in power, which usually emphasized maximization of personal benefits at the expense of public interest.

Furthermore, rational choices in preference of poor commitment and response by other Nigerians who are stakeholders in the health reform project also affect the success of the scheme. Such stakeholders, either apathetic to their roles under the health reform agenda or are more concerned with personal gains (at the expense of public interest) are serious enemies to the reform process. This is particularly so because, in absence of such local enemies, if international health aid are improperly packaged or have other hidden motives, patriotic and dedicated Nigerians should reject or re-define the terms of such 
aid to ensure favourable returns on the nation's health system. Ogu (2007) made similar observations when she insisted that the new scramble for Africa through globalization, market for finished goods and development aid, must be on terms agreed upon by Africans. Thus, African development projects should be owned and controlled by Africans.

Against the above background, local enemy related factors that constitute obstacles to realization of health reform objectives in Nigeria include:

a. Lack of adequate political will and commitment on the part of leadership in Nigeria at LGA, state and federal levels.

b. Corruption and misappropriation of health reform aid/grants.

c. Misuse of vehicles and equipment procured for health reform projects.

d. Poor community participation in PHC and other reform driven health projects.

e. Implementation inconsistencies in health development projects.

f. Inadequacy of local budget for health services and to fulfill government counterpart cash contribution (GCCC) to international organizations and donor agencies.

g. Boko Haram security threat and intra/inter community conflicts in parts of Nigeria.

h. Poverty and other socio-cultural factors like belief systems and ethnic loyalty.

Historical Perspective on the Nigerian Healthcare Delivery System and According to Adebola (2008), the issue of reform is not new to the Nigerian healthcare delivery system. Several reform programmes (or attempts thereof, conscious or otherwise) to improve health services have been made in the past. The traditional health care system that existed among the ethnic nationalities encountered improvements during the pre-colonial medical system which was set up by European missionaries and traders. Similarly, in the wake of British colonization, the first Nigerian Colonial Development Plan of the 1940s provided for unitary health service system. Thereafter, came the Era of Regionalization in the 1950s when the national health system stopped being unitary; and the regional governments started to run independent and sometimes parallel health systems with the federal government. At independence, the Second National Development Plan that heralded the post independence era in the 1960s followed. Unfortunately, the plan did not articulate a health system with clear levels, nor assign responsibilities to the three levels of government (Adebola, 2008; Asuzu, 2002).

The Third National Development Plan of the 1970s was a rather ambitious plan with Basic Health Services Scheme as its focus (Adebola, 2008). It was quite elaborate in its health reform package with emphasis on infrastructure and auxiliary health manpower development. Nonetheless, there was yet no clear policy framework in place to guide health as at that time. 
In 1978, the international community agreed at Alma Ata Conference and the subsequent Riga Conference, that primary health care is most only viable approach towards optimum health for the people (WHO, 1978). The resolution shifted policy thrusts in the area of health in Nigeria to Primary Health Care (PHC) System. According to FMOH (2007) the PHC package provided for:

(a) Allocation of responsibility for primary, secondary and tertiary health care to different tiers of government and restriction not to wade outside of their primary responsibility if they have not substantially fulfilled it first.

(b) Involvement of appropriate community health professionals - nurses (as community health nurses) and medical officers of health for every local government area in the country etc.

(c) State governments to staff and equip district hospitals as the major aspect of their secondary health care services for which they hold primary responsibility. This is the first part of the primary health care support (i.e., referral) system; without which PHC will not work.

(d) The training and retraining of professional and auxiliary primary health care workers (in situations that engender team work).

(e) The orientation, reorientation and continuing education of the political class and community leaders, especially the local government chairmen and councilors support for PHC and secondary health care.

With PHC and prior to the economic travails of the mid-1980s, the health sector witnessed robust growth, principally as a result of unfettered support by government, coupled with assistance from international donor agencies. Except in rural areas, there was marked improvement in access to health care available at public hospitals and clinics. However, by 1985, this positive development had screeched to a grinding halt, owing to a plurality of factors, two of which were economic decline and military usurpation of power (Adeola, 2005).

The last phase of military dictatorship (1983-1998) massively altered the socio-political and economic landscape of Nigeria. The military was largely non-responsive to deficiencies and continued rot of the health system. Such decay was evident in the patchwork of public health infrastructure strewn across the country, most of which were severely understaffed and suffer extreme shortages of even the most basic equipment and medicine. Also, escalated costs of treatment meant that millions of people were effectively shut out of the system at that time (NPC, 2004; Odutola, 2004; Adeola, 2005).

With the demise of military dictatorship in 1999 and emergence of new democratic dispensation awareness of the numerous problems prompted civilian regime between 1999 and 2007 to opt for health sector reform. The thrust of the reforms was at making health care accessible, equitable, 
affordable as well as cost-effective and efficient. The civilian administration of Olusegun Obasanjo embarked on health reforms in order to reposition the Nigerian public health sector to be responsive to the health needs of Nigerians and to ensure healthier, longer and more productive lives.

The National Health Insurance Scheme (NHIS) and other initiatives are presently being pursued at three levels of government as part of reform agenda. Although the health reform project has been far from perfect, the development and implementation of related programmes represent a significant departure from the deficiencies of the past, at least in terms of openness and greater public participation.

Unfortunately, as Nigerians eagerly await full benefits from the health reform processes, several security challenges are emerging and constituting additional obstacles to the realization of the reform objectives. Notable among the security challenges are Boko Haram insurgence in the North, kidnapping particularly in the Southeast, flood disasters, communal clashes and violence in Plateau state etc.

\section{Security and Related Problems Confronting Health Sector Reforms in Nigeria}

The Nigerian healthcare delivery system and the health sector reform project encounter numerous challenges. There have been several implementation setbacks resulting in limited successes. Some of the factors contributory to such poor performance discussed by scholars including Ichoku (2004), Audu (2002), Chukwunweike (2005), Metiboba (2011), Chukwu (2012) are reviewed below:

Size and diversity of the country: The size and population of Nigeria, her diversity in culture, differential social and economic conditions including wide variations in health resource availability across geo-political zones of the country are major challenges to health planning. In addition, rapid population growth in the country has overstretched the social resources. Nigeria's past failures to take population figures into cognizance in national planning has negative implications for health planning. As a result, the provision of health facilities and services has remained inadequate for ever increasing population (Asuzu, 2002; Berman, 1995).

Stewardship Systems: Chukwu (2012) observes that in Nigeria commitment to good governance is weak. Leadership in Nigeria has over the years defectively conceptualized and implemented health policies and programmes especially at the lowest level which has responsibility for provision of primary healthcare services. The lack of political will to confront health challenges and high levels of irresponsibility among leaders often affects financing, assessment of costeffectiveness and accountability in health interventions.

Poor Quality of Care/Service Delivery: Health facilities are inadequate in Nigeria (Yohesor, 2004). This includes health centers, personnel, medical 
equipment and other resources. This inadequacy is worse in rural areas (FMOH, 2004). The state of existing facilities is often poor due to lack of maintenance. Furthermore, health care services are fragmented, skewed in distribution, limited in coverage and of poor quality. Also, the referral systems are weak.

Health Care Financing and Resource Generation: In Nigeria, health care expenditure is not only low, but two thirds of it is out-of pocket, thus reducing access especially to the poor and vulnerable groups (Ogunbekun, 2004; Ichoku, 2004; Metiboba, 2011). There is currently no system for monitoring health expenditure, in terms of distribution. Attempts toward National Health Accounts are at best elementary. There is scarcity of all resources for the health sector (drugs, infrastructure, equipment and human resources).

Human Resources for Health: Human resources for health is not only inadequate, their distribution and skills mix is a serious source of concern. The issue of poor motivation and low remuneration has adverse effects on the morale of professional health workers. The issue of strikes and brain drain also constitute problems, especially as many qualified personnel decide to seek lucrative jobs outside the shores of the country (Audu, 2002).

Poverty: Poverty remains pronounced in Nigeria. Over $70 \%$ of the populace still lives below the poverty line of one dollar (\$1.00) per day (GMR, 2005). The situation is worst in rural areas due to unemployment and poor development of human capital. The problems of malnutrition, ignorance, disease and unemployment under an increasingly sick economy constitute serious affronts to successful implementation of health reforms in Nigeria. Poverty makes it difficult for the populace to pay for their health needs. Unfortunately, payment for health services is based on consumption and not ability to pay. Poverty is thus a major factor in poor utilization and access to healthcare services particularly in the rural areas of the country.

Low Awareness and Community Participation: Limited knowledge or low awareness about health reform project in rural areas and even among many urban dwellers is a disservice to the success of health reform efforts in Nigeria. A comprehensive public enlightenment and healthcare coverage of entire Nigerian society is crucial (Metiboba, 2011).

Pharmaceuticals and Medical Supplies: Fake, sub-standard, adulterated and unregistered drugs are prevalent (NAFDAC, 2003). This is in spite of highly visible and commendable efforts of NAFDAC. Efforts aimed at local research and developments of pharmaceutical raw materials are yet to yield the desired results due to low funding of research and development. 
Weak, Inappropriate Health Systems: The primary health care system on which the national health policy is anchored is experiencing serious challenges. Apart from not being affordable, accessible and acceptable to most Nigerians, it also fails to adequately address the increasing burden of disease in the country. New and re-emerging diseases have created a new scenario in service delivery as many diseases have defied conventional medical technology (WHO, 2000).

Entrenched Corruption in Millennium Development Goals (MDGs) Implementation: A major challenge to the realization of MDGs is poor commitment to its policy implementation. The implementation of MDGs has been characterized by deeply entrenched corruption, gross inefficiency and wastefulness (UNDP, 2004; Nwokeoma, 2009). Corruption has been a major problem because "it makes the country unattractive to investors as it raises the cost and risk of doing business in the country" (UNDP, 2004).

Incessant Man-made Insecurity/threats: There are several man-made security threats such as kidnapping, political and economic related assassinations and extra-judicial killings, etc. These make Nigeria unattractive to investors (foreign or local) as it raises the cost and risk of doing business in the country. Cases of bombing particularly in northern states of Nigeria by the Boko Haram sect have complicated health reform and healthcare delivery problems by destroying facilities, increasing casualties and killing or wounding health workers.

Poor Health Budgets: Both at the federal, state and local government levels, the budgetary provisions for the public health care system are not commendable. Poor funding for public health delivery and a reliance on privatization and commercialization of healthcare in the country has led to a situation in Nigeria where the health sector is unable to effectively meet the vast needs of the country (Ichoku, 2004; Ogunbekun, 2004).

Unharnessed Providers: Orthodox medicine is complemented by traditional medicine in Nigeria. Traditional healers provide low-cost care and are usually the first point of contact for many residents of rural areas The government has not fully harnessed all the available health care resources in the public and private sectors in the country. Consequently, there is limited public private partnership in health care delivery. This is despite the fact that substantial proportion in the population preferred the services of traditional and private sector providers. There is therefore need to strengthen both traditional medicine and private sectors.

Cost Recovery: The resource generation for the health sector is inadequate. This is due to various factors like increasing poverty in the country, poor allocation of resources by government and payment for out of pocket services 
by healthcare providers. All these make it difficult for the populace to pay for their health needs, leading to poor mobilization of funds from the private sector (Ogunbekun, 1999).

Duplication of Projects Lack or Inconsistent Policy Thrust: Frequent changes in policy direction and legislation are also problematic. There is the problem of duplication of projects in the same areas by the federal government and multilateral donor agencies (Nwokeoma, 2009). Duplication of efforts in the past has led to redundancy and waste of resources that could have yielded greater dividend had they been employed elsewhere.

\section{Prospects/Recommendations for achieving Health Reform Agenda in Nigerian State}

Insecurity in its broad manifestations of poverty, economic underdevelopment, poor administration, lack of political will, the Boko Haram insurgence, communal clashes, etc. have made Nigeria's yearning towards achieving health reform agenda and the MDGs in 2015 very uncertain. Nonetheless, there are high prospects that the country could overcome the odds given her huge human and material resources. What is required is focused and responsive leadership at all levels, with the political will to harness the resources and maximize growth and development. Such leadership must positively overhaul the conceptualization and implementation of health policies and programmes and make progress in areas of fight against HIV/AIDS, sustainability of the environment, reduction in child and maternal mortality, as well as lessening poverty, all of which are targets of both MDGs and health reform agenda. In specific terms, the understated measures are crucial for achievement of truly reformed and sustainable healthcare in Nigeria:

a. Dialogue is an essential instrument for peace building in communities. There are high prospects of achieving health reform goals if the option of dialogue is embraced by both government and dissenting or aggrieved groups. Such groups should be encouraged to state their grievances for possible resolution. When conflicts are resolved, peaceful atmosphere are created which keep health reform agenda effectively on course.

b. Economic empowerment strategies must be pursued more vigorously. Poverty alleviation schemes including employment and microfinance initiatives should be expanded. Such measures will break the vicious circle of poverty which contributes negatively to meeting health reform goals in Nigeria.

c. Aggressive public enlightenment should be embarked upon to reduce tendencies that threaten peace and security. Such enlightenment should focus on negative effects of conflicts and insecurity on national development. It should also address mitigation measures for conflict and the benefits of peace to nation building. 
d. Government should strengthen primary health care to provide a solid foundation for Nigeria's health services. It should be revitalized to deliver basic health care, including routine immunization, to all the nooks and crannies of the country. Primary health care must be at the heart of Nigeria's health policy because it is the level nearest to the populace. Addressing needs at the primary level will drastically reduce the burden on secondary and tertiary levels. An improvement strategy that focuses on 'manpower (people), process and equipment refinement' is recommended. This will reintroduce efficiency to primary health care and ensure that it fully fulfils its role as first point of call.

e. There is need for integrated approach to development that will focus on all sectors, including health. Such a model should not only address the risk factors of disease but also cross-cutting issues and linkages between health and security including, financing for health.

f. It is equally necessary to promote sound policy to increase productivity in the agricultural sector (NPC, 2007). What this connotes is that economic growth should lead to poverty alleviation and betterment of the lots of the poor masses or ordinary Nigerians (Federal Government of Nigeria, 2004).

g. One of the key issues in the health sector is the dearth of human resource - medical personnel, health workers, etc -- which is really serious in the rural areas. Government should address this gap by training more people. Innovative incentive regimes should help to attract some of the best and brightest to the rural and semi-urban areas, and motivate them to remain and provide service to such communities.

h. Infrastructural development and assets maintenance in all primary, secondary and tertiary health institutions should be vigorously pursued; this will include developing facilities that will ensure that the whole gamut of advanced medical care is available to all our people locally.

i. Partnership with pharmaceutical companies in the production of essential drugs for use in hospitals is very crucial. Research and development of local drugs should be a priority issue. Furthermore, NAFDAC should be strengthened to prevent the manufacture and importation of fake and substandard drugs which endanger the lives of Nigerian citizens.

j. Poor leadership and political instability have been a major contributory factor for unsuccessful implementation of most government policies and programmes in the area of health care delivery. Therefore, good leadership and political stability is desirable to provide enabling environment for the implementation of health reform agenda. 
k. Accreditation of programmes and institutions, and certification of health care personnel employed by different organizations should be regularly conducted with appropriate registration boards.

1. More financial and other incentives should be provided to prevent the high turn-over of health workers. There is need for the local government and other tiers of government to increase their allocation to the health sector. Local governments should be more inward-looking and aggressive in the area of internally-generated revenue. This is to reduce the dependence on the federation account in financing health programmes (Abdulraheem, Olapipo and Amodu, 2012).

m. Supervision, monitoring and evaluation of programmes should be pursued with vigor. Manpower required for this very important assignment must be provided at LGA, state and federal levels. They must be adequately trained. The Nigerian health policy should give priority to training.

\section{Conclusion}

Several bottlenecks militating against successful implementation of health reforms in Nigeria have been highlighted in this paper. In addition to far reaching recommendations earmarked, the need for introduction of beneficiary/community participation in the reform process was strongly emphasized. This would enhance successful health reform implementation and sustainability. Beneficiary involvement should not only be at the level of planning or payment of associated dues or levies, but must extend to critical levels of monitoring, implementation and evaluation. Furthermore, reform efforts founded on egalitarian principles which will ensure socially and economically productive and fulfilling life to every individual are more likely to succeed. Above all, since health reform is not a magic wand that would end the catalogue of Nigeria's health problems, it must align itself with other efforts to achieve growth and development to the Nigerian state. The creation of an enabling environment where lives and property are secure is certainly crucial for full participation of urban and rural residents, complemented by government's political commitment to ensure realization of health reform agenda and Millennium Development Goals (MDGs) in Nigeria.

\section{References}

Abdulraheem, I.S.; Olapipo, A.R. and Amodu, M.O. 2012. Primary HealthCare Services in Nigeria: Critical Issues and Strategies for Enhancing the Use by the Rural Communities. Journal of Public Health and Epidemiology. 4(1):5-13.

Adebola, S.A. 2008. "An Overview of Developments in Health Care Administration in Nigeria (1960-2005)" Saliu, O. (ed.). Perspective on 
Nation-building and Development in Nigeria. Lagos: Concept Publications Limited.

Anyaehie, U. \& Nwobodo, E. 2004. Administrative Responsibilities of Community-Funded Health Insurance Scheme in Nigeria. Nigerian Medical Practitioner. 45(2):5-8.

Asuzu, M.C. 2002. The necessity for a health systems reform in Nigeria. Journal of Community Medicine \& Primary Health Care. 16(1):1-3.

Audu, I. 2002. "NHIS will Abolish Industrial Strikes." Nigeria Tribune Tuesday, January, 1. 13.

Berman, P. 1995. Health sector reform: making health development sustainable. Health Policy. 32:13-28.

Chukwu, O. 2012. Leadership Health playing second fiddle to security, infrastructure.http://www.leadership.ng/nga/articles/17468/2012/02/27/hea lth_playing_second_fiddlesecurityinfrastructure_\%E2\%80\%93_chukwu.ht $\mathrm{ml}$.

Chukwunwike, O. 2005. National Health Insurance Scheme: A Disseratum. http://-a,tribalfusion.com.

CSIS. 2005. HIV/AIDS in Nigeria: Toward sustainable US engagement. Washington DC. www.csis.org/media/csis/pubs/0508_hivaids_nigeria.pdf.

Ebigwei, S.O. 2005. "Let common sense Prevail on National Health Insurance. Leadership "Experts score healthcare system low on World Health Day", (7 April, 2012). http://allafrica.com/stories/201204080162.html.

Elbe, S. 2005. AIDS, security, biopolitics. International Relations. 19(4):403419.

Elbe, S. 2006. Should HIV/AIDS be securitized? The ethical dilemmas of linking HIV/AIDS and security. International Studies. Quarterly. 50(1):119-44.

Federal Ministry of Health. 2001. Nigerian National Health Insurance Scheme and Improvement of the Health Status of Nigerians. Ministry of Health, Abuja.

Federal Ministry of Health. 2004. Healthcare in Nigeria. Annual Bulletin of the Federal Ministry of Health. Abuja, Nigeria.

Federal Ministry of Health (FMOH). 2004. Report of Proceeding of $52^{\text {nd }}$ National Council of Health. 35-40.

Federal Ministry of Health (FMOH) Abuja. 2007. Health Sector Reform Programme Strategic Thrusts with a Logical Framework and a Plan of Action. 10-15.

Federal Office of Statistics, and UNICEF. 2000. Multiple Indicator Cluster Survey 1999. Lagos: Federal Office Statistics and UNICEF.

Global Monitoring Report (GMR). 2005. From Consensus to Momentum, World Bank Publication.

Haralambos, M.; Holborn, M. \& Heald, R. 2004. Sociology: Themes and Perspectives. London: Haaeper and Collins Publishers. 
Ichoku, H. 2004. Income redistributive effects of the health care financing system in Nigeria. Retrieved December 14, http://www.meetings\&workshops/DAKAR/pdffile/Hyacinthementa.

Koeman, J. 2003. Progress on 'Ndo-Nwanne' Health Scheme. Informal Report to Head of Department, NHIS. Enugu, Nigeria.

Lee, K. and McInnes, C. 2004. A conceptual framework for research and policy. Ingram, A. (ed.). Health, foreign policy and security: Towards a conceptual framework for research and policy. London: Nuffield Trust. www.nuffield-trust.org.uk/ publications/detail.asp?id=0\&prID $=21$.

Metiboba, S. 2011. Nigeria's National Health Insurance Scheme: The Need for Beneficiary Participation. Research Journal of International Studies 6/2. Nigeria: Euro Journals Publishing, Inc.

National Agency for Food, Drugs, Administration and Control. 2003. The Menace of Fake and Substandard Product in our Health Systems. NAFDAC Bulletin. Abuja, Nigeria. 27:18-21.

National Planning Commission (NPC). 2007. Nigeria Millennium Development Goals 2006 Report. Abuja: NPC.

Neilson, T. 2005. AIDS, Economics and Terrorism. New York: Global Business Coalition on HIV/AIDS.

NHIS. 2001. 'National Health Insurance.' Paper presented at 32nd Annual http://www.herfon.org/docs/Harmonised-NATIONAL-HEALTH-BILL20$11 \% 20$-doc.pdf.

NHIS. 2001. National Health Insurance Scheme: Operational Guidelines, National Health Insurance Scheme Abuja, Nigeria.

NHIS. 2005. National Health Insurance Take off Presidential Research and Communication Unit. Abuja, Nigeria. December 10, 2007. www.Nigeriafrist.Org/Article255.Hstml.

National Intelligence Council (NIC). 2002. Intelligence community assessment: The next wave of HIVIAIDS: Nigeria, Ethiopia, Russia, India, and China. ICA 2002-04D. Washington DC.

Nwokeoma, J. 2009. "Why Nigeria may not meet the Millennium Development Goals", [Online]: Retrieved from http://www.nigeriansinamerica.com/articles/3530/1/-why-Nigeria-may-not-meet-the-MillenniumDevelopmentGoals. (Accessed on 10 October 2009)

Odutola, A. 2004. Nigeria's Health Sector Reform-www.afronets.org/archive/200401.

Ogu, J.U. 2007. Leadership and Development: The Challenge of Africa, Abuja: Presidential Inauguration Lecture, May 28.

Ogunbekun, I.; Ogunbekun, A. \& Orobaton, N. 1999. Private Health Care in Nigeria: Walking the Tightrope. Health Policy and Planning. Oxford: University Press. 14(2):81-174.

Ogunbekun, I. 2004. Health Insurance: A viable Approach to Financing Health Care in Nigeria. Retrieved December 15, 2007. http://www.heapol.oxfordjournals.org. Report of the Vision 2020 National Technical Working Group on Health July, 2009. 
South African White Paper on Defence. 1996. Pretoria: Department of Defence.

UNDP. 2004. National Millennium Development Goals Report 2004--Nigeria. New York: Oxford University Press for the United Nations Development Programme.

United Nations Population Fund. 2002. State of the World Population. NY: UNFPA.

WHO (World Health Organization). 2000. World Health Report 2000 - Health System: Improving Performance. Geneva.

WHO (World Health Organization). 2007. World health report 2007: A safer future. Global public health security in the 21st century. Geneva.

WHO. 1978. Declaration of Alma Atta. United Nations, New York.

World Bank - World Development Report. 2000. Investing in health. New York: Oxford University Press.www.csis.org/media/csis/pubs/0508_hivaids_nigeria.pdf.

Yohersor, A. 2004. Social health Insurance scheme that works: Recommendation to NHIS. Abuja: Vast Communications Publishers. 